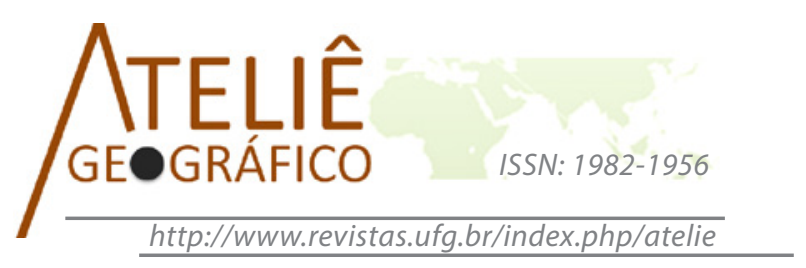

\title{
Território Usado: o elo perdido no federalismo brasileiro
}

\section{Used Territory: The lost link in the Brazilian Federalism}

\author{
Territoire Usé: le lien perdu dans le fédéralisme brésilien
}

\author{
Denis Ricardo Carloto \\ Universidade Federal do Tocantins \\ denis@uft.edu.br
}

\begin{abstract}
Resumo
O texto tem como objetivo refletir sobre a categoria território usado na constituição da federação brasileira com o intuito de diminuir as desigualdades socioespaciais existentes no país. Entende-se que o território usado é um dos elos para o fortalecimento do federalismo brasileiro na construção de uma nação forte, democrática e consolidada. Reforça-se a ideia de que o federalismo é pacto entre diferentes que se uniram em prol da igualdade e combate as desigualdades, mantendo as diversidades e diferenças. Igualdade esta tanto social quanto política, econômica e cultural não para homogeneizar a sociedade, mas para garantir os usos mais igualitários. Não é também entendido como a igualdade das unidades federadas no que se refere ao tamanho da superfície e da população, como muitas vezes planejada.
\end{abstract}

Palavras-chave: Território Usado; Federalismo; Desigualdades Socioespaciais; Fragmentação; Solidariedade.

\begin{abstract}
The objective of the text is to consider carefully the category used territory in the constitution of the Brazilian federation with the aim of reducing the socialspatial inequalities that there are in the world. We understand that the used territory is one of the links for the strengthening of the Brazilian federalism in the building of a consolidated democratic strong nation. We give additional force to the idea that federalism is an agreement among the different units. And these have joined together on the behalf of equality to strive against inequalities, maintaining the diversities and differences. equality is not to make homogeneous but to guarantee more equalitarian uses. Also we do not understand as the equality of the federal units concerning the size of the area and the population as it is planned many times. Keywords: Used territory; Federalism; Socialspatial inequalities; Fragmentation; Solidarity.
\end{abstract}




\begin{abstract}
Résumé
Le texte a comme objectif réfléchir sur la catégorie territoire usé dans la constitution de la fédération brésilienne qui a comme but réduire les inégalités sociospatiaux existentes au pays. On comprend que le territoire usé est un lien pour le renforcement du fédéralisme brésilien dans la construction d'une nation forte, démocratique et consolidée. On renforce l'idée de que le fédéralisme est un pacte entre différents, qu' on se réunit en faveur d'égalité et d'affronter les inégalités, en conservant les diversités et les différences. Égalité celle-ci autant sociale que politique, économique et culturelle, pas pour homogénéiser la societé, mais pour assurer les usages plus égalitaires. Cela n'est pas aussi compris comme l'égalité des unités fédérés dans ce qui concerne la taille de la surface et de la population, comme beaucoup de fois planifiées.

Mots-clé: Territoire Usé; Fédéralisme; Inégalités; Sociospatiaux; Fragmentation; Solidarité.
\end{abstract}

\title{
Introdução
}

A segurança da tradição pode ser suficientemente reconfortante para bloquear qualquer possibilidade inovadora. (MURRAY BOOKCHIN, 1999, p. 25)

O território usado é um dos elos para o fortalecimento do federalismo. Reforça-se a ideia de que o federalismo é pacto entre diferentes que se uniram em prol da igualdade e combate as desigualdades, mantendo as diversidades e diferenças. (DALLARI, 1986; PROUDHON, 2001). Igualdade esta tanto social quanto política, econômica e cultural não para homogeneizar a sociedade, mas para garantir os usos mais igualitários. Não entende-se como igualdade das unidades federadas no que se refere ao tamanho da superfície e da população, tampouco o território entendido como a simples porção do espaço no qual se exerce poder.

Santos (2000) ao presentear-nos com 'O papel ativo da Geografia: um manifesto" demonstrou que é preciso considerar o espaço geográfico como sinônimo de território usado, sendo que este deve ser compreendido como resultado do processo histórico e base material da sociedade.

A compreensão do espaço geográfico como sinônimo de espaço banal obriganos a levar em conta todos os elementos e a perceber a inter-relação entre os fenômenos. Uma perspectiva do território usado conduz à ideia de espaço banal, o espaço de todos, todo o espaço. Trata-se do espaço de todos os homens, não importa suas diferenças; o espaço de todas as instituições, não importa a sua força; o espaço de todas as empresas, não importa o seu poder. Esse é o espaço de todas as dimensões do acontecer, de todas as determinações da totalidade social. (SANTOS, 2000, p. 104)

Desta maneira o território usado sendo considerado no processo de construção da federação brasileira, aqui denominado de amálgama federativo. Esse compreendido 
pelo pacto entre as unidades por liberdade, igualdade, autonomia e descentralização do uso coerente do território pelo povo, governo, organizações e instituições objetivando a soberania da nação (CARLOTO, 2014). Assim, o amálgama federativo é a força política na compreensão e construção do território usado. O território é usado por tudo e por todos, e somado a engenharia política do federalismo tem a oportunidade de gerar igualdades entre as unidades federadas bem como os sujeitos sociais que historicamente se tornaram desiguais pelo seu uso. Daí a dificuldade de compreender como os Estados aceitaram e ainda hoje aceitam as desigualdades existentes geradas a partir da formação e constituição do pacto federativo. Entende-se que são as diferenças que unem os entes na formação de um Estado Federativo, entretanto, as diferenças servem para fortalecer a totalidade do país e a construção da nação soberana. Portanto, o princípio da igualdade é que deveria impedir a existência e geração de mais desigualdades entre as unidades e, consequentemente, dos cidadãos que se uniram com o objetivo de fortalecer a todos e a tudo.

A igualdade nesse pacto não está única e exclusivamente em dimensões espaciais, ou seja, unidades de mesmo tamanho territorial. Entende-se que está nas igualdades de condições e de possibilidades de uso do território. Ressalta-se que o espaço geográfico, compreendido como território usado, é "formado por um conjunto indissociável, solidário e também contraditório, de sistemas de objetos e sistemas de ações, não considerados isoladamente, mas como o quadro único no qual a história se dá”. (SANTOS, 2002c, p.63). Portanto, o espaço geográfico assim compreendido como sistemas de objetos e ações, influem, bem como, determinam as relações socioespaciais, sendo a política a força motriz na constituição do federalismo e do território usado e não a economia ${ }^{1}$.

Santos (2007) demonstrou que o valor dos indivíduos depende do lugar de onde ele está, e com razão, pois vivemos no território que, historicamente, foi construído de forma e maneira desiguais, destinando politicamente o seu uso.

\title{
Usos desiguais no federalismo brasileiro
}

De acordo com Santos (2001) na globalização as contradições entre o que é externo e o que é interno aumentaram no Estado, sendo o "território nacional da economia internacional". Porém é o Estado nacional que tem o poder de comandar e normatizar a política no território.

\begin{abstract}
É o Estado nacional que, afinal, regula o mundo financeiro e constrói infraestruturas, atribuindo, assim, a grandes empresas escolhidas a condição de sua viabilidade. O mesmo pode ser dito das instituições supranacionais (FMI, Banco Mundial, Nações Unidas, Organização Mundial do Comércio), cujos editos ou recomendações necessitam de decisões internas a cada país para que tenham eficácia. O Banco Central é, frequentemente, essa correia de transmissão (situada acima do Parlamento) entre uma vontade política externa
\end{abstract}

1. Para Maria Adélia Aparecida de Souza (2013) é a política e não mais a economia que dita os rumos do mundo - anotações pessoais. 
e uma ausência de vontade interior. Por isso, tornou-se corriqueiro entregar a direção desses bancos centrais a personagens mais comprometidas com os postulados ideológicos da finança internacional do que com os interesses concretos das sociedades nacionais. (SANTOS, 2001, p. 78)

O pacto baseado em Proudhon (2001) pressupõe autonomia, liberdade e equilíbrio entre as unidades federadas, no qual tanto umas como as outras tem obrigações recíprocas de igualdade. No caso brasileiro, o pacto resultou na fragmentação do território em milhares de unidades e pelo uso desigual das partes. Gerou desigualdades pela escolha política de se distribuir os objetos técnicos no território, que estão concentrados em determinados lugares. Há necessidade de se repensar o federalismo brasileiro como um pacto de ordem estrutural, pensando na sociedade e não em interesses corporativos ou de núcleos familiares. Desta maneira, Santos (2007) nos alerta que foram realizados no país "pactos funcionais" em vez de "pactos estruturais".

Pactos funcionais interessam a parcelas da população e a interesses localizados, mas não atingem o âmago das relações sociais fundamentais. Criar um novo município, por exemplo, pode atender a interesses eleitorais (ocasionais) de um partido ou a interesses financeiros de um grupo. O mesmo se pode dizer em relação ao surgimento de novos estados e territórios. O que faz falta é a proposição de um pacto territorial estrutural, conjunto de propostas visando a um uso do território coerente com um projeto de país e parte essencial desse projeto. (SANTOS, 2007, p.133)

Desta maneira reitera-se a falta de pacto no federalismo brasileiro. Um pacto cujo interesse atende, historicamente, uma pequena parcela da população e não a sua totalidade demonstra que os princípios da federação foram alijados e o território alienado. Coaduna-se a ideia do amálgama federativo com o pacto territorial estrutural de Santos (2007). A partir desta ideia, o projeto a ser desenvolvido no país com a concepção de que o território é e deve ser usado por tudo e por todos, irá combater diretamente as desigualdades geradas no Brasil. A questão a ser debatida na construção da nação é: o que fazer com as desigualdades?

O território é causa de maior desigualdade entre firmas, instituições e sobretudo entre os homens. Em lugar de se tornar o desejado instrumento de igualdade individual e de fortalecimento da cidadania, o território manterá o seu papel atualmente perverso, não apenas alojando, mas na verdade criando cidadãos desiguais, não apenas pelo seu lugar na produção, mas também em função do lugar onde vivem. (SANTOS, 2007, p.134)

A ideia apresentada pelo autor reforça que a fragmentação do território se dá, principalmente, pela desigualdade no uso do território causada pelas características das dinâmicas do atual período histórico - técnico-científico-informacional e não simplesmente pelo fatiamento desproporcional da terra. As desigualdades como apresentadas são socioespaciais, e, portanto, o território usado, o elo perdido no processo histórico do federalismo brasileiro, é a quintessência na construção do país e na geração da nação soberana. 
Santos (2001, p. 79) ao analisar a importância do espaço geográfico com a globalização afirma que os agentes "mais poderosos se reservam os melhores pedaços do território e deixam o resto para os outros". E o Brasil não escapa a essa lógica, onde a fragmentação se apresenta novamente pelo uso corporativo do território. Para Santos (2001) a competitividade entre as empresas arrastam, também, os Estados a competirem pela lógica e força normativa e econômica de produção.

Cada empresa, porém, utiliza o território em função dos seus fins próprios e exclusivamente em função desses fins. As empresas apenas têm olhos para os seus próprios objetivos e são cegas para tudo o mais. Desse modo, quanto mais racionais forem as regras de sua ação individual tanto menos tais regras serão respeitosas do entorno econômico, social, político, cultural, moral ou geográfico, funcionando, as mais das vezes, como um elemento de perturbação e mesmo de desordem. Nesse movimento, tudo o que existia anteriormente à instalação dessas empresas hegemônicas é convidado a adaptar-se às suas formas de ser e de agirem mesmo que provoque, no entorno preexistente, grandes distorções, inclusive a quebra da solidariedade social. (SANTOS, 2001, p. 85)

As empresas hegemônicas agem sobre o território, e, desta maneira criam lógicas e ordens, que para Santos (2001) é desordeira, pois é distorcido do entendimento dos lugares.

Dentro de um mesmo país se criam formas e ritmos diferentes de evolução,
governados pelas metas e destinos específicos de cada empresa hegemônica,
que arrastam com sua presença outros atores sociais, mediante a aceitação
ou mesmo a elaboração de discursos "nacionais-regionais" alienígenas ou
alienados. (SANTOS, 2001, p. 87)

A fragmentação se dá pelos usos desiguais, no qual as melhores partes do território são escolhidas de acordo com a lógica de produção do momento, portanto são voláteis e pelas empresas hegemônicas, que por sua vez arrastam os Estados a participarem dessa lógica globalizante e alienante. Como as 'melhores partes' são reservadas e recebem quinhões diferenciados e concentração das benesses em detrimento de outras partes, geram e criam usos e cidadãos desiguais resultando na fragmentação do território.

A falta de entendimento do que é e do que se pode proporcionar a compreensão e ação do território usado, tanto dos governos quanto das empresas, coadunando com o amálgama federativo é que se vislumbra a erradicação das desigualdades socioespaciais no país. Assim, reforça-se que o espaço é de todos os homens, instituições e empresas, não importando suas diferenças, forças e poderes.

Para demonstrar como o território usado não é praticado no desenvolvimento da história do federalismo brasileiro, utiliza-se mapas do Brasil e tabelas selecionados a partir de temas correlacionados com a educação, o trabalho e a saúde. Estes informativos foram obtidos através dos Indicadores sociodemográficos e de saúde do Brasil - 2009; do Censo demográfico de 2010 e do Atlas de saneamento de 2011, todos do IBGE. As temáticas ilustradas e apresentadas têm como referência os direitos sociais garantidos pela Carta Magna de 1988. 


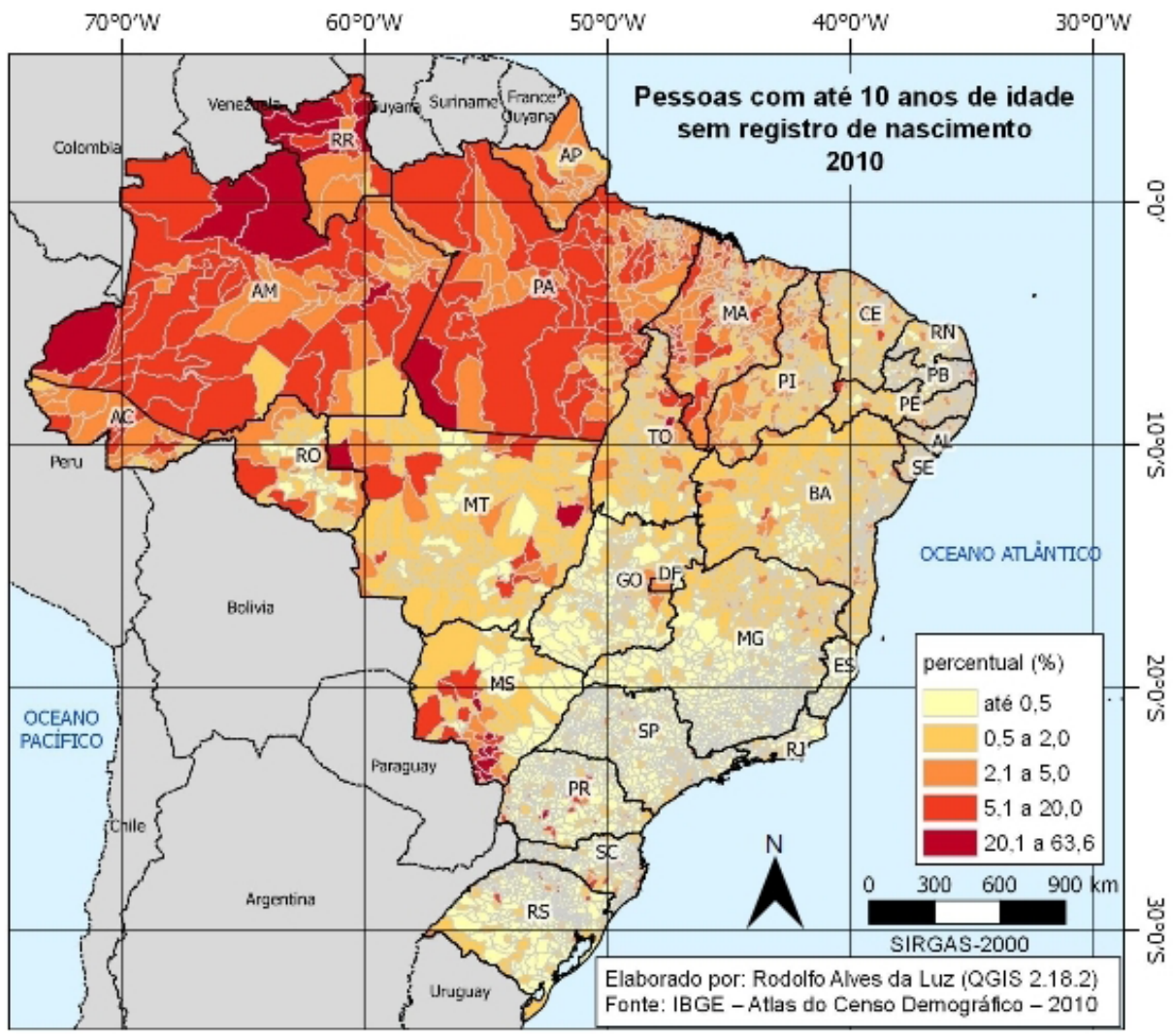

Figura 01. Brasil - Pessoas com até 10 anos de idade sem registro de nascimento por município

Como se pode observar na figura 01 a base é municipal, portanto, há 27 municípios, com destaque em vermelho escuro, mais críticos que possuem índices entre 20,1 a 63,6 por cento de crianças com até 10 anos sem registro de nascimento. É evidente a concentração nos Estados da região norte do país. Assim, entende-se que essas crianças são 'invisíveis' aos olhos das políticas públicas dificultando e determinando os usos que fazem do território. Tal perversidade implica em outros desdobramentos como acesso a saúde e educação, afinal, essas crianças não possuem o documento necessário para serem atendidas pelas políticas de acesso a direitos sociais garantidos na Constituição de 1988 .

As figuras 02, 03 e 04, a seguir, apresentam índices de analfabetismo por idade. As figuras aqui apresentadas são compreendidas como recursos para auxiliar a interpretação sendo ferramenta indispensável para a ação política direcionada com o objetivo de coibir e diminuir as desigualdades que são socioespaciais. 


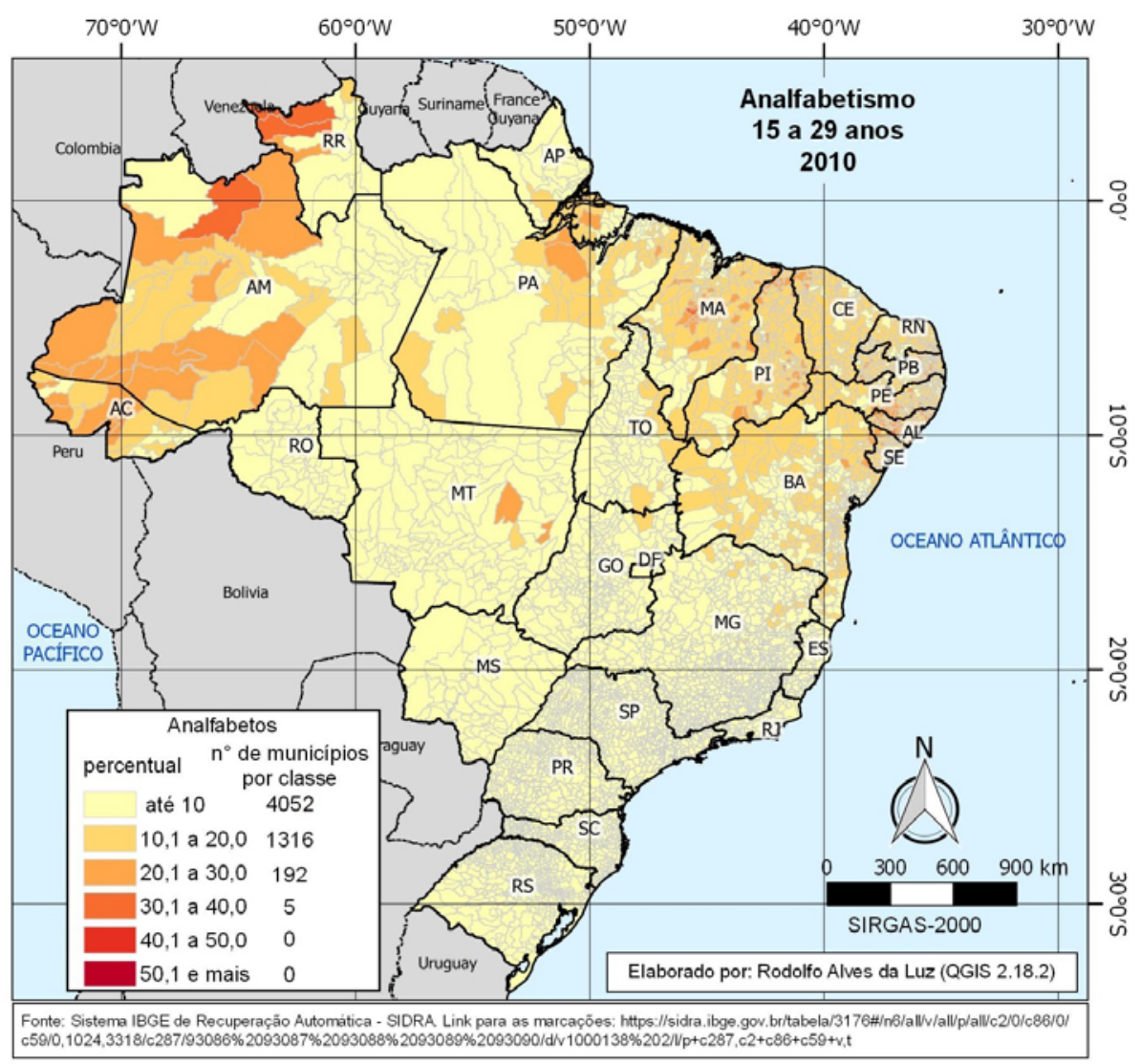

Figura 02. Brasil - Índice de Analfabetismo - 15-29 anos por município

A maioria dos jovens entre 15 a 29 no Brasil inteiro tem percentual abaixo de 10\% de analfabetismo em 4052 municípios. Porém há ainda cinco municípios no país, conforme Figura 2, com índice entre 30,1 e 40\% de analfabetos; e 192 municípios entre 20,1 a 30\%; e 1316 municípios com indices entre 10,1 a 20\% destes jovens analfabetos.

Na figura 03 que representa índice de analfabetismo na população entre 30 a 59 anos há aumento considerável de municípios, sendo, 23 com índice acima de 50\% desta população de analfabetos. Em até $10 \%$ da população desta faixa etária de analfabetos estão em 2339 municípios; entre 10,1 a 20\% em 1239 municípios; entre 20,1 a 30\% em 842 municípios; entre 30,1 a 40\% em 816 municípios; entre 40,1 a 50\% em 306 municípios. Importante destacar que não há municípios apresentados na figura 02 Analfabetismo entre 15 a 29 anos - com índice de analfabetismo acima dos 40\% como há na faixa etária entre 30 e 59 anos apresentados na figura 03 . 


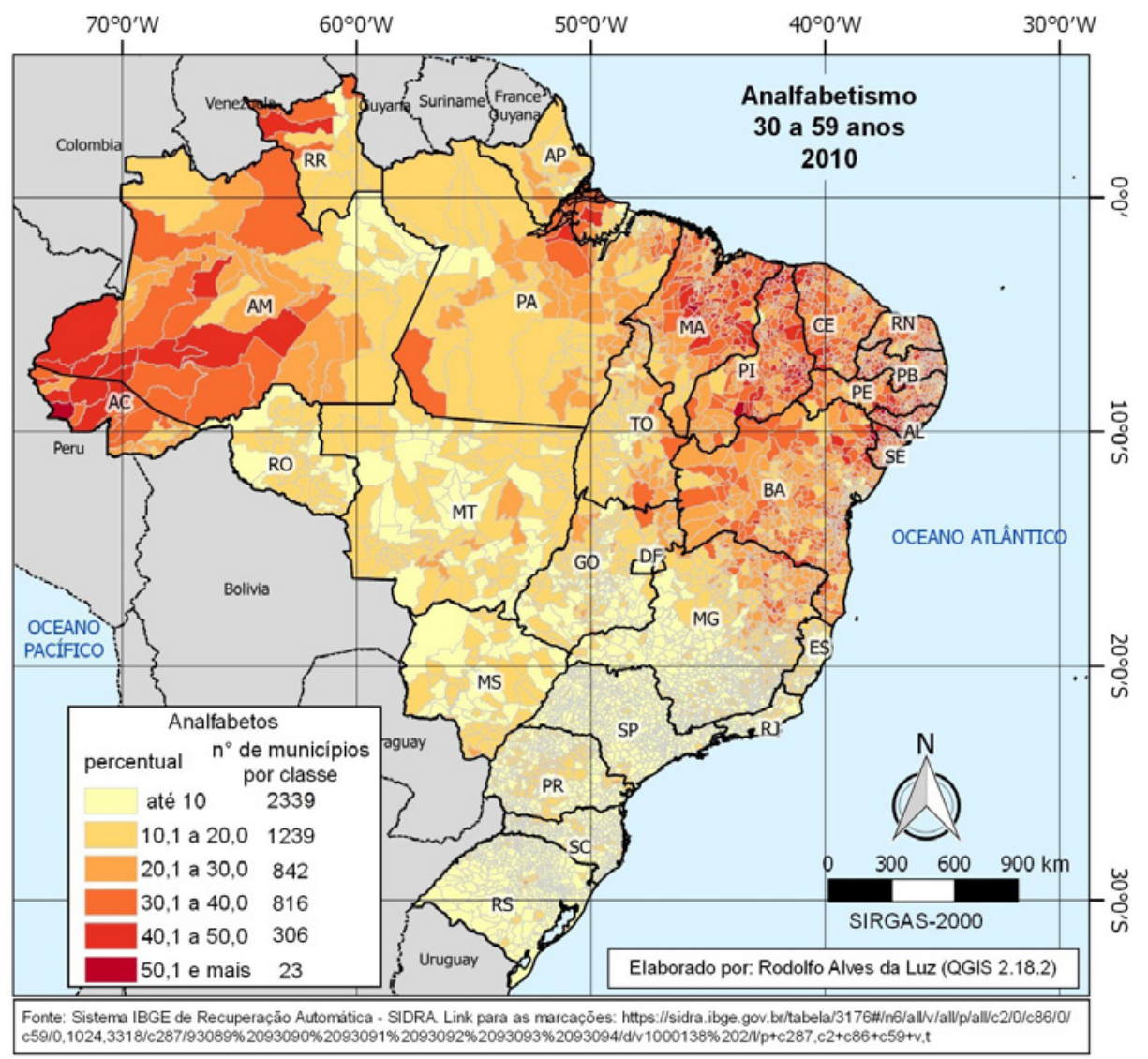

Figura 03. Brasil - Índice de Analfabetismo 30-59 anos por município

Na figura 04 inverte-se completamente os índices de analfabetismo entre a população acima dos 60 anos de idade em comparação com a figura 02 da população mais jovem. A concentração dos analfabetos acima dos 60 anos encontra-se localizados nos municípios das regiões Norte e Nordeste. Conforme é apresentado na figura 04, apenas 130 municípios do Brasil apresentam índices abaixo dos 10\% da população acima de 60 anos analfabeta. Entre 10,1 a 20\% de analfabetos estão em 770 municípios; entre 20,1 a 30\% em 1076 municípios; entre 30,1 a 40\% em 885 municípios; entre 40,1 a 50\% em 695 municípios; e acima dos 50\% de analfabetos acima dos 60 anos estão em 2009 municípios brasileiros. 


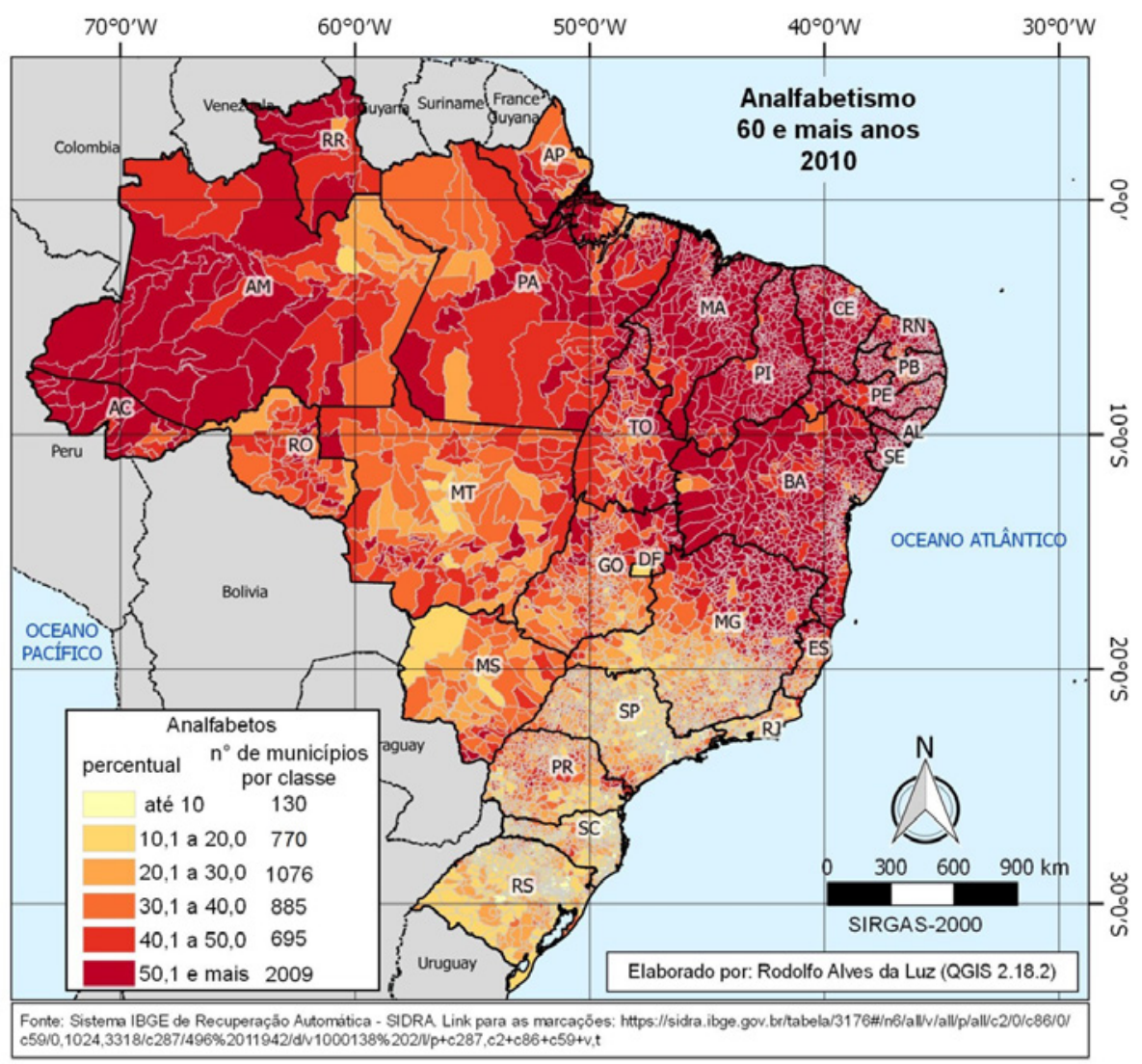

Figura 04. Brasil - Índice de Analfabetismo 60 anos ou mais por município

As figuras demonstram a concentração das perversidades nos estados e municípios da região Nordeste seguido pela região Norte do país. É possível verificar que os sujeitos sociais acima dos 60 anos são os mais afetados quando se trata de analfabetismo. A Educação é um direito garantido pela Constituição de 1988, porém ainda não está a serviço de todos e nem em todas as localidades, o que interfere na vida de cada um limitando-os ao uso do território e restringindo-os de existirem como cidadãos completos. Temos um exemplo concreto de lugares de escassez e opacos como demonstrou Santos (2002c). É possível afirmar que as novas gerações, representados na figura 02 pelos jovens entre 15 a 29 anos, que tiveram suas vidas escolares definidas pelas políticas públicas da Constituição de 1988, usufruem com mais intensidade dos direitos garantidos nesta Carta Magna, considerando que os índices de analfabetismo são menores em comparação com os sujeitos sociais com mais de 60 anos. Esses nasceram e viveram boa parte de suas vidas sendo regida pelas Constituições anteriores a de 1988, no qual a educação não era obrigação do Estado. 
As figuras 05 e 06, a seguir, apresentam dados de 2000 e 2010 com percentual de pessoas que sabem ler e escrever.

No ano de 2000 havia 1089 municípios com percentual acima de 80\% da população que sabe ler e escrever e estão concentrados nas regiões Sul e Sudeste do país. Enquanto que a maioria dos municípios com índices abaixo dos $60 \%$ da população que sabe ler e escrever estão concentrados na região Nordeste e Norte, conforme apresentado na figura 05 .

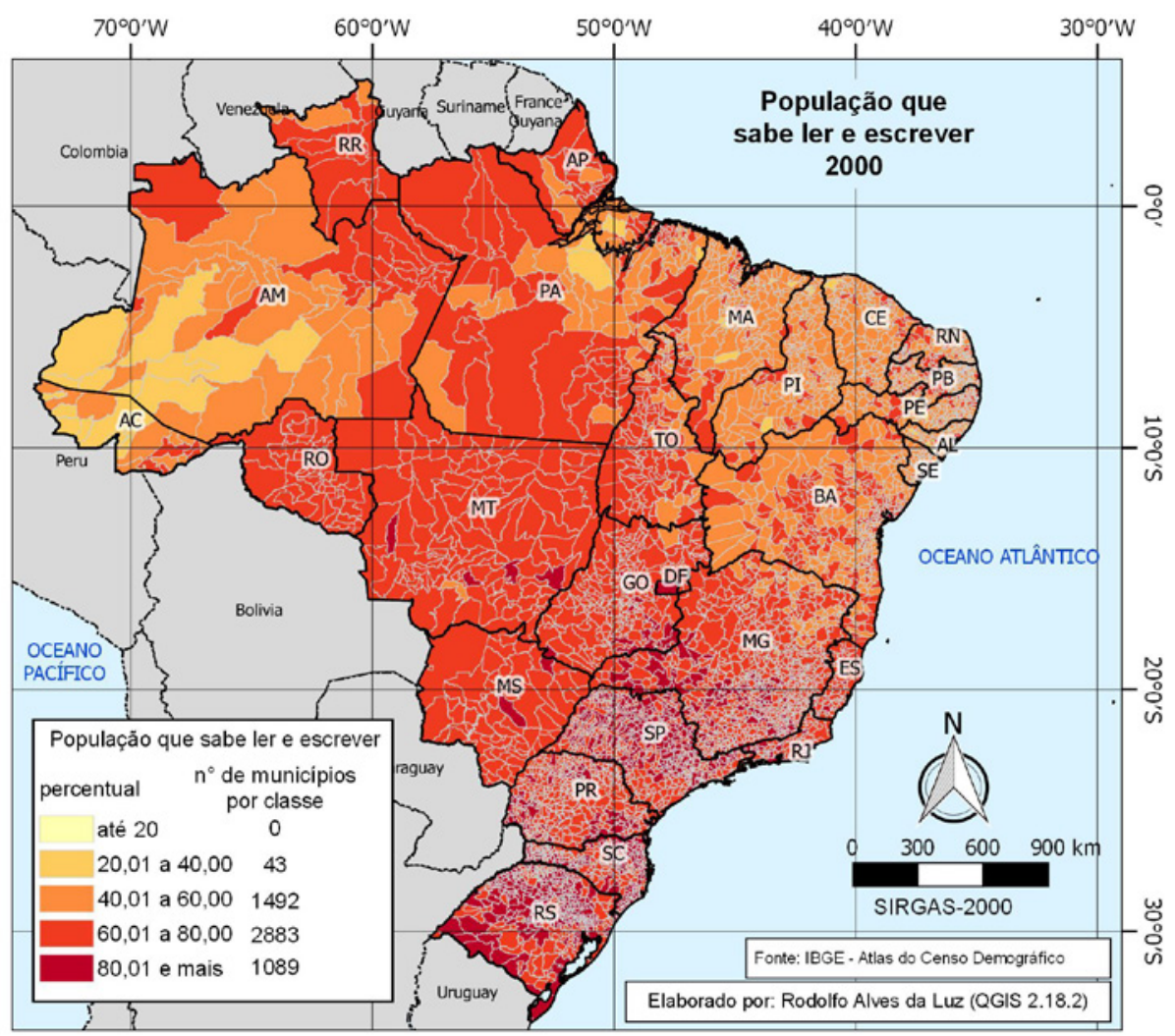

Figura 05. Brasil - Percentual da população que sabe ler e escrever 2000

É visível que a maioria população que sabe ler e escrever está concentrado na região Sul e Sudeste, porém em 2010 se expande para quase todo o território nacional graças as políticas públicas implantadas principalmente na primeira década do século XXI, conforme apresentado na figura 06 abaixo. Em 2010 o percentual acima de $80 \%$ da população que sabe ler e escrever salta para 3650 municípios, em comparação com os 1089 municípios no ano de 2000, e estão distribuídos de maneira mais homogênea pelo território nacional. 


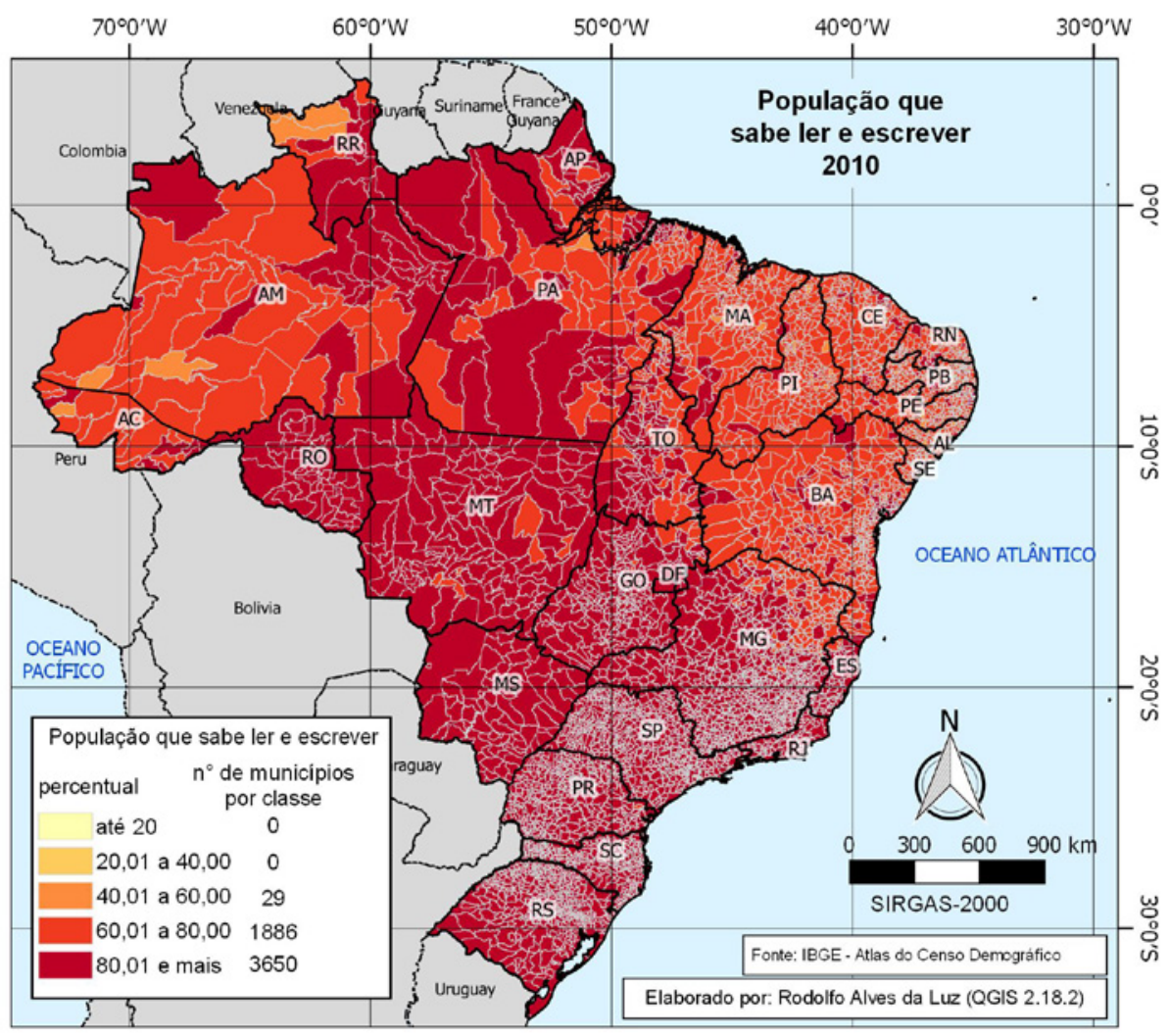

Figura 06. Brasil - Percentual da população que sabe ler e escrever 2010

É notório o aumento das pessoas em todo o Brasil que sabem ler e escrever, mas não entende-se que isso seja passível de comemoração, pois o país está entre as maiores economia do mundo e o analfabeto funcional não reúne condições necessárias para acessar, por exemplo, postos de trabalho com maiores remunerações, sendo assim os usos do território são restritos para estas pessoas. Nota-se que no ano 2000 havia 5507 municípios enquanto que em 2010 salta para 5565. Atualmente há 5570 municípios.

As Figuras 07 e 08 seguintes representam a porcentagem da população jovem que frequenta o ensino médio e superior, respectivamente. As figuras também são de base municipal demonstrando os lugares de escassez e abundancia no que se refere à educação formal no país garantida como direito social na Constituição de 1988.

Importante destacar que a maioria dos municípios tem até 50\% de seus jovens de 15 a 17 anos frequentando a escola, ou seja, 50\% estão fora da escola em 3261 municípios, enquanto que acima de $50,01 \%$ até $94,74 \%$ são 2304 municípios que tem a maioria dos jovens frequentando o ensino médio no país, conforme informações da figura 07. Há ainda muito que se fazer com relação a inclusão dos jovens brasileiros na educação 
formal, formando cidadãos e erradicando de vez o analfabetismo e a evasão escolar por parte da população mais pobre deste país. Fortalecendo assim a soberania nacional. A nação só é soberana quando a totalidade da sua população também for soberana.

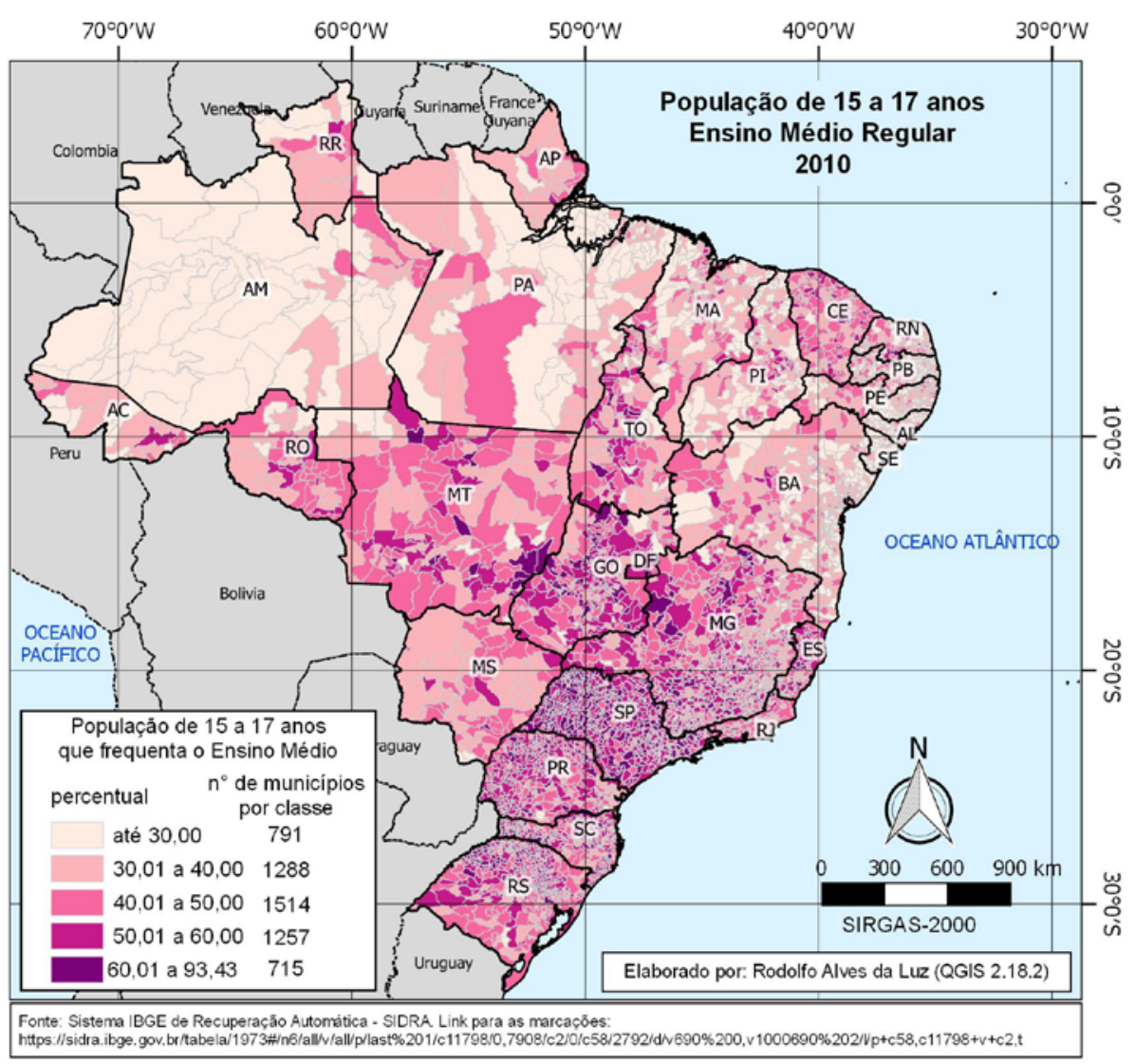

Figura 07. Brasil - Percentual da população jovem que frequenta o ensino médio por município

A figura 08 que demonstra o quantitativo de jovens por município que estão cursando o ensino superior é bastante desigual e perversa. De todos os municípios no Brasil apenas 330 têm entre $20,01 \%$ a $43,80 \%$, sendo esta a porcentagem máxima, dos jovens cursando alguma graduação e estes mais uma vez encontram-se concentrados em poucos Estados da federação brasileira. 


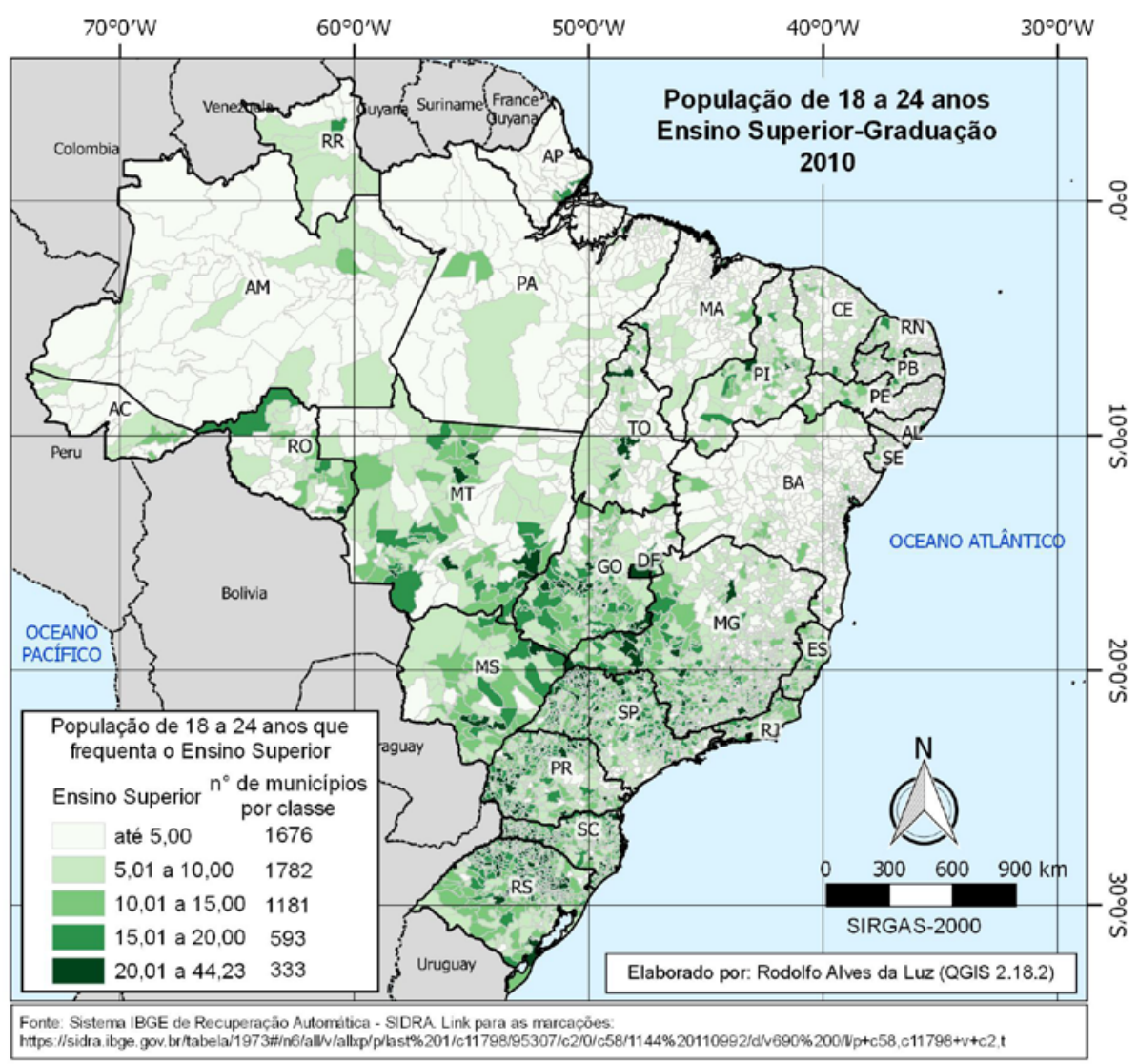

Figura 08. Brasil - Percentual da população jovem que frequenta o ensino superior por município

Consequentemente se há desigualdades na educação formal há também desigualdades no rendimento médio e no emprego informal conforme apresentados nas figuras 09 e 10. Destaca-se que onde há maior concentração dos empregos informais há também maior concentração dos rendimentos mais baixos por domicílio, ambos estão nos Estados da região Nordeste do país, principalmente.

Na Figura 09 os municípios de tom mais claro, 1765, são o que têm menor rendimento médio domiciliar entre 538,47 a 1.100,00 sendo a maioria concentrados na região Nordeste. Apenas 179 municípios, os mais escuros da figura, tem rendimento médio, em reais, entre $3.000,01$ a $6.512,79$ sendo estes o maior rendimento. Somente 179 dos 5565 (dados 2010), ou seja apenas 3,22\% dos municípios tem a renda mais alta dentre as demais classes, é evidente a concentração de renda no país bem como as desigualdades socioespaciais. 


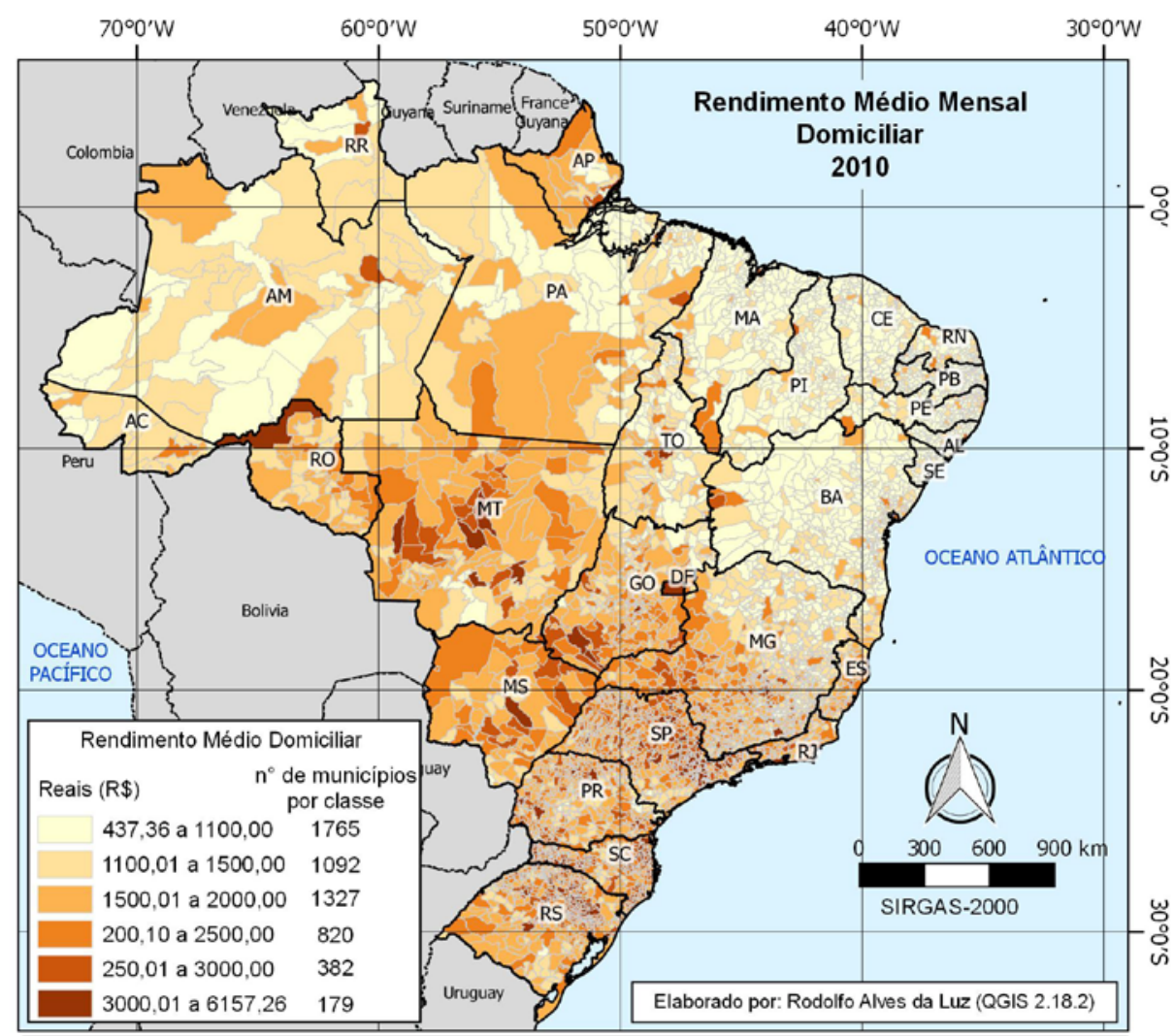

Fonte: Sistema IBGE de Recuperação Automática - SIDRA. Link para marcaçöes:

https://sidra.ibge.gov.br/tabela/3562\#/n6/all/v/847/p/all/c1/6795/c12065/100285/d/v847\%202/l/p+c1,v+c12065,t

Figura 09. Brasil - Rendimento médio domiciliar por município

Na figura 10, os pontos mais escuros representam entre 46,1 a $69 \%$ da população no emprego informal em 569 municípios. O percentual entre 36,1 a 46\% está em 1184 municípios; entre 28,1 a 36\% em 1193 municípios; entre 20,1 a 28\% para 1230 municípios e apenas 1389 municípios abaixo dos $20 \%$ da população no emprego informal.

São perceptíveis as desigualdades existentes no território. A possibilidade de sobreposição das figuras demonstraria que o analfabetismo, o ensino superior estão diretamente relacionados ao rendimento médio e ao exercício do emprego informal. Estas perversidades tem lugar na federação brasileira e reforçam a necessidade de compreensão do território usado. Há lugares de escassez e há lugares de abundância, tanto de pessoas quanto de objetos e ações.

Se há no país informações detalhadas das perversidades por município, dos 5570 existentes no atual período, qual é dificuldade da União, dos estados e dos municípios para resolvê-los e diminuí-los? 


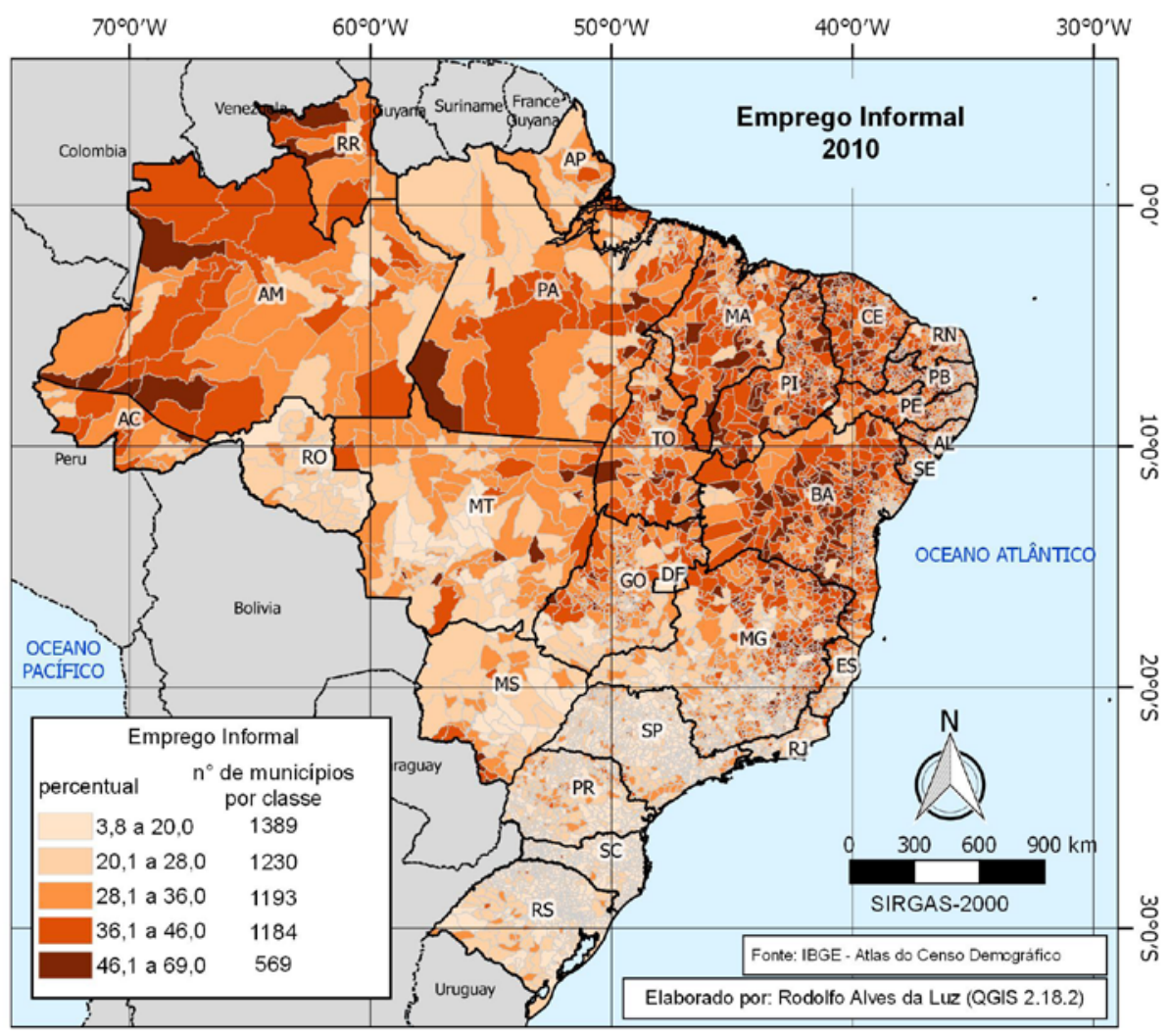

Figura 10. Brasil - Emprego informal por município

\section{Considerações finais}

O objetivo ao apresentar as figuras também é pela necessidade de incorporar o território usado como categoria central para compreensão e ação das políticas públicas mais eficazes, além de demonstrar que o federalismo brasileiro bem como a democracia e a soberania deste país ainda estão em processo de construção e consolidação pelos três entes. O espírito comunal, que Tocqueville (1987) destacou dos cidadãos estadunidenses, precisa ser aceso nos cidadãos brasileiros, com o intuito de usar o território de maneira mais igualitária.

O federalismo tem como princípio as relações recíprocas de igualdade entre os entes e, portanto, de usos mais solidários do que compulsivos. Desta maneira a federação brasileira se encontra distante de tais princípios, o que a torna desigual.

Historicamente o desenvolvimento do território brasileiro se fez a partir da dependência econômica de outras nações e suas empresas. Portanto foram geradas desigualdades e fragmentação territorial pelo uso corporativo e pela criação de pactos funcionais em detrimento de um pacto territorial estrutural. Entende-se que esse pacto 
se realizará pelo entendimento do território usado como categoria de análise social, que reflita as decisões politicas tomadas pelo Estado.

Para os atores hegemônicos, o território usado é um recurso, garantia da realização de seus interesses particulares. Desse modo, o rebatimento de suas ações conduz a uma constante adaptação de seu uso, com adição de uma materialidade funcional ao exercício das atividades exógenas ao lugar, aprofundando a divisão social e territorial do trabalho, mediante a seletividade dos investimentos econômicos que gera um uso corporativo do território. Por outro lado, as situações resultantes nos possibilitam, a cada momento, entender que se faz mister considerar o comportamento de todos os homens. Os distintos atores não possuem o mesmo poder de comando, levando a uma multiplicidade de ações, fruto do convívio dos atores hegemônicos com os hegemonizados. Dessa combinação temos o arranjo singular dos lugares.

Os atores hegemonizados têm o território como um abrigo, buscando constantemente se adaptar ao meio geográfico local, ao mesmo tempo que recriam estratégias que garantam sua sobrevivência nos lugares. É neste jogo dialético que podemos recuperar a totalidade. (SANTOS, 2000, p. 108)

Se os dados apresentados por Estado e Região fossem diagnosticados a partir das localidades, as diferenças e desigualdades seriam ainda mais escandalosas. É mister considerar os lugares no federalismo brasileiro, pois é onde a vida acontece e onde o uso do território se apresenta tal como ele é. Este é o elo faltante na composição de uma federação mais igualitária e solidária com intuito de fortalecimento e soberania da nação.

\section{Referências}

ANDERSON, George. Federalismo: uma introdução. Tradução: Ewandro Magalhães Jr., Fátima Guerreiro. Rio de Janeiro: Editora FGV, 2009.

ARISTÓTELES. A Política. São Paulo: editora Escala, s/d.

BOOKCHIN, Murray. Municipalismo libertário. Trad. J.P. Oliveira et al. São Paulo: $\mathrm{Nu}-\mathrm{Sol}, 1999$

. O municipalismo libertário. In: BOOKCHIN, Murray; BONIO, Paul; ENCKELL, Marianne. O bairro, a comuna, a cidade... Espaços libertários! Trad. Plínio Augusto Coêlho. São Paulo: Imaginário, 2003.

CARLOTO, Denis Ricardo. Por uma federação de lugares da desigualdade a solidariedade. Tese de Doutorado apresentada ao Departamento de Geografia da Faculdade de Filosofia, Letras e Ciências Humanas da Universidade de São Paulo, 2014.

DALLARI, Dalmo de Abreu. O Estado Federal. São Paulo: Editora Ática, 1986.

HAMILTON, Alexander; MADISON, James; JAY, John. O Federalista. Trad. Hiltomar Martins Oliveira. Belo Horizonte: Editora Líder, 2003. 
IBGE (Instituto Brasileiro de Geografia e Estatística). Redes e fluxos do território gestão do território 2014. Ministério do Planejamento Orçamento e Gestão. Rio de Janeiro, 2014. Disponível em www.ibge.gov.br Acesso em: 10 jun 2014.

IBGE (Instituto Brasileiro de Geografia e Estatística). Síntese de indicadores sociais: uma análise das condições de vida da população brasileira 2013. Ministério do Planejamento Orçamento e Gestão. Rio de Janeiro, 2013. Estudos e Pesquisas Informação demográfica e socioeconômica, n. 32. Disponível em www.ibge.gov.br Acesso em: 10 jun 2014.

IBGE (Instituto Brasileiro de Geografia e Estatística). Atlas de Saneamento 2011. Ministério do Planejamento Orçamento e Gestão. Rio de Janeiro, 2011. Disponível em www.ibge.gov.br Acesso em: 10 jun 2014.

IBGE (Instituto Brasileiro de Geografia e Estatística). Redes e fluxos do território ligações aéreas 2010. Ministério do Planejamento Orçamento e Gestão. Rio de Janeiro, 2010. Disponível em www.ibge.gov.br Acesso em: 10 jun 2014.

IBGE (Instituto Brasileiro de Geografia e Estatística). Indicadores sócio-demográficos e de saúde no Brasil - 2009. Ministério do Planejamento Orçamento e Gestão. Rio de Janeiro, 2009. Estudos e Pesquisas Informação demográfica e socioeconômica, n. 25. Disponível em www.ibge.gov.br Acesso em: 10 jun 2014.

PROUDHON, Pierre Joseph. Do Princípio Federativo. São Paulo: Nu-Sol: Imaginário, 2001.

SANTOS, Milton. Pobreza urbana. 2 ed. São Paulo: Hucitec, 1979.

. Por uma geografia nova: da crítica da geografia a uma geografia crítica. $3^{\mathrm{a}} \mathrm{Ed}$. São Paulo: Hucitec, 1986.

. Metamorfoses do espaço habitado: fundamentos teóricos e metodológicos da Geografia. 4 ed. São Paulo: Hucitec, 1996.

Modo de produção técnico-científico e diferenciação espacial. In: Revista Território. Rio de Janeiro, ano IV, nº 6, PP. 06-20, jan-jun, 1999.

. O papel ativo da geografia: um manifesto. In: Revista Território. Rio de Janeiro, ano V, no 9, PP. 103-109, jul-dez, 2000.

. Por uma outra globalização: do pensamento único à consciência universal. 5 ed. Rio de Janeiro: Record, 2001.

. O retorno do território. In M. Santos, M. A. A. Souza, \& M. L. Silveira (Orgs.), Território: globalização e fragmentação. São Paulo: Annablume/Hucitec/ANPUR, 2002a.

. O dinheiro e o território. In: Território Territórios / Programa de Pós-Graduação em Geografia - PPGEO-UFF/AGB - Niterói, 2002b.

. A natureza do espaço. Técnica e tempo. Razão e emoção. São Paulo: Edusp, 2002c. 384p. 
. (org) O país distorcido: o Brasil a globalização e a cidadania. São Paulo: Publifolha, 2002d.

. Economia Espacial: críticas e alternativas. Tradução: Maria Irene de Q. F. Szmrecsányi. 2. ed. São Paulo: Edusp, 2003.

O Espaço dividido: os dois circuitos da economia urbana dos países subdesenvolvidos. Tradução: Myrna T. Rego Viana. 2. ed. São Paulo: Editora da USP, 2004.

. Da totalidade ao Lugar. São Paulo: Edusp, 2005.

. O espaço do cidadão. 7. ed. São Paulo: Edusp, 2007.

. Espaço e método. 5. ed. São Paulo: Edusp, 2008.

. Técnica, Espaço, Tempo: globalização e meio técnico-científico-informacional. 5 ed. São Paulo: Edusp, 2008b.

. Metrópole corporativa fragmentada: o caso de São Paulo. 2. ed. São Paulo: Edusp, 2009a.

. Por uma economia política da cidade: o caso de São Paulo. 2. ed. São Paulo: Edusp, 2009c.

- Geografia e planejamento: o uso do território - geopolítica. In: Revista Eletrônica:

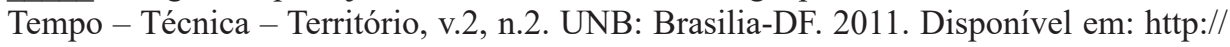
inseer.ibict.br/ciga/index.php/ciga/issue/view/14 Acessso 30 jul 2014.

SANTOS, Milton; SILVEIRA, Maria Laura. O Brasil: território e sociedade no início do século XXI. $5^{\mathrm{a}}$ ed. Rio de Janeiro: Record, 2003.

SOUZA, Maria Adélia Aparecida de. Debate sobre a crise do planejamento. Espaço \& Debate, São Paulo: Cortez, ano 1, n. 1, jan. 1981, p. 103-126

. Geografias das desigualdades: globalização e fragmentação. In: SANTOS, Milton; SOUZA, Maria Adélia A. de; SILVEIRA, Maria Laura (Org.). Território: Globalização e fragmentação. São Paulo: Hucitec, 1994. p.21-28

. A identidade da metrópole. São Paulo: Ed. da USP, 1994b.

. Política e território: a geografia das desigualdades. Campinas, 5 jun. 2002. Texto apresentado no Fórum Brasil em questão - Universidade de Brasília.

. (org) Território brasileiro: usos e abusos. Campinas: Territorial, 2003.

. O II PND e a política urbana brasileira: uma contradição evidente. In: DEÀR, Csaba; SCHIFFER, Sueli Ramos (Org.). O processo de urbanização no Brasil. São Paulo: Edusp, 2004. p. 111-143

. O lugar como resistência: uma dimensão da realidade do futuro. In: SILVA, Maria Auxiliadora da; TOLEDO JR., Rubens de; DIAS, Clímaco César Siqueira (org.). Encontro com o pensamento de Milton Santos: o lugar fundamentando o período popular da história. Salvador: Empresa Gráfica da Bahia, 2005. 284p. p.189-198 
. A geografia da solidariedade. Geotextos, vol. 2, n. 2, p. 171-178, 2006.

. A metrópole e o futuro: A dinâmica dos lugares e o período popular da história. In: A metrópole e o futuro: refletindo sobre Campinas. Campinas: Territorial, 2008.

. Território e lugar: a busca de uma Pastoral urbana mais orgânica. In: BRIGHENTI, Agenor (org). Pastoral urbana: categorias de análise e interpelações pastorais. Brasília: Edições CNBB, 2010. (p. 41-63).

TOCQUEVILlE, Alexis de. A democracia na América. Trad. Neil Ribeiro da Silva. 2. ed. Belo Horizonte: Ed. Itatiaia; SP: Ed. da USP, 1987.

\section{Denis Ricardo CARLOTO}

Doutor em Geografia pela Universidade de São Paulo, mestre em Geografia pela Universidade Federal do Paraná e graduado em Geografia pela Universidade Estadual de Londrina. Atualmente é Professor Adjunto do curso de Geografia da Universidade Federal do Tocantins - Câmpus de Porto Nacional e coordenador do LABUTO - Laboratório de Pesquisa em Geografia Política e Usos do Território brasileiro.

Endereço: Rua s/n, Qd.13, Jardim dos Ipes. Cep: 77500.000. Porto Nacional TO.

E-mail: denis@uft.edu.br

Recebido para publicação em agosto de 2016

Aprovado para publicação em dezembro de 2016 